\title{
Arbor
}

\section{Emoción y relato}

\author{
Marisa Pérez Juliá
}

Arbor CLXVII, 697 (Enero 2004), 125-156 pp.

El artículo está estructurado en dos partes. La primera parte se centra en una revisión sobre el concepto de emoción en las distintas áreas de conocimiento: la Neurología; la Psicología (la Psicología Cognitiva y la Psicobiología), la Retórica; áreas que, desde nuestro enfoque, no se hallan entre sí tan distantes. De hecho, en opinión de Ledoux (1996), la Neurología puede servir de inspiración a la Psicología. La concepción del circuito límbico, en el que podemos deslindar distintos subsistemas que interactúan entre sí, nos lleva a hablar de la emoción en términos de modularidad y a aproximarla así a las demás funciones cognitivas: percepción, atención, memoria, lenguaje. En el concepto de emoción hay un núcleo perceptivo, ya que entre el objeto desencadenante y la propia reacción emocional media una valoración que introduce al sujeto de la enunciación en el enunciado. Dado, pues, el paso hacia un enfoque perceptivo, relacionamos las dimensiones importantes de la experiencia emocional: activación/excitación; Atracción/repulsión; Expansión/Retracción; Control/no control con las leyes gestálticas que operan en la interacción entre los sujetos y están presentes, también, en los distintos niveles del lenguaje, dando cuenta de unos mecanismos lingüisticos $u$ otros. La segunda parte del artículo contiene una descripción lingüistica de algunos fragmentos de relatos en los que predomina el desprecio, la ira o el miedo.

\section{Algunos puntos de partida para una Lingüística emocional}

Sin duda, la imbricación de la emoción en el lenguaje y, sobre todo, el modo en que se manifiestan las diferentes emociones en el relato, lo que 
constituye el objeto de nuestra reflexión teórica, tropieza con algunas dificultades ya de entrada. En los estudios más recientes sobre la emoción, llama nuestra atención, por un lado, el carácter interdisciplinar de tales estudios y, al mismo tiempo, la fragmentación del panorama de investigación, es decir, cierta ausencia de relación entre las distintas áreas de conocimiento que se han ocupado de este tema. Ello ha deparado en un vacío sobre la emoción y su inscripción, en tanto proceso cognitivo en el que las reacciones fisiológicas así como su expresión verbal y no verbal están mediatizadas por la valoración que hacemos de la situación, en la actuación lingüística. Su inscripción en la actuación lingüística se ha limitado, hasta el momento, al estudio de aspectos muy parciales: la morfología apreciativa con los tipos de diminutivos; la interjección; el estudio contrastivo del léxico emocional; las metáforas que nos hablan del modo en que conceptualizamos las emociones. No obstante, es evidente que la comprensión de una emoción pone en juego algo más que el significado de una palabra sola o aislada. De hecho, la palabra feliz por si sola no provoca en el oyente o lector un sentimiento de felicidad.

En este sentido, el semiótico Paolo Fabbri (1998) hacía algunas consideraciones que, en nuestra opinión, perfilan, de un modo certero, las limitaciones del estado actual de la cuestión: hemos llegado a una tipología (o deberíamos, mejor, hablar de tipologías) de emociones que gozan de mayor o menor consenso, según los casos; hemos llegado a una semiótica -la utilización del término "Semiótica» resulta, creemos, pertinente- de los signos emocionales pero no a una Lingüística de las emociones que, asumiendo la posición de Fabbri, iría más allá del significado semántico, de la estructura gramatical para centrarse en el análisis del relato, si tenemos en cuenta que -como planteaba Descartes en Las Pasiones del alma o Aristóteles en su Retórica- la pasión es el punto de vista sobre la acción, por parte de quien la recibe, y sobre las transformaciones que la misma acción genera. Decía Germán García en relación a un texto de Jean Pierre Dupuy de 1992 que lleva por título El Sacrificio y la envidia: «las pasiones son la entrada del sujeto en el lenguaje. Porque no hay otra manera de ver de qué manera el sujeto de la enunciación entra en el enunciado». Y lo cierto es que, tampoco, hemos dado un paso hacia la Psicología del Lenguaje, planteándonos las posibles operaciones cognitivas que subyacen bajo la proyección de las emociones en el relato.

Las investigaciones, en el ámbito de la Neurología, realizadas por LeDoux (1996) han contribuido a perfilar mejor nuestra visión del circuito límbico con zonas neuronales estrechamente conectadas entre sí pero con funciones, al mismo tiempo, diferentes y, para nada, alejadas del pensamiento, razonamiento o conciencia, de ahí que la oposición emoción-razón 
sea una falsa dicotomía que haya que desterrar. De hecho, Ledoux considera que la emoción y la cognición son funciones mentales separadas pero en interacción; funciones que se asientan en sistemas cerebrales distintos pero que, por otro lado, no dejan de interactuar. Según Hardcastle (1999: 245), las investigaciones neurocientíficas han atribuido una gran importancia a la amígdala, ignorando que, en el procesamiento afectivo, se pone en juego un feedback muy complejo. De hecho, tendríamos que considerar, en opinión de este autor, el sistema límbico como un circuito o espacio de múltiples dimensiones que ofrece distintos recorridos o trayectorias; cada zona representa una dimensión o variable, es decir, un posible punto de partida en la realización de las conexiones sinápticas y en la activación de una emoción o grupo de emociones afines.

... We can map the firing patterns of these circuits over time to a trajectory in a multidimensional phase space (Each dimension would represent each variable that determines how the firing pattern might go; the phase space then would be a region that includes all and only the possible activity patterns in the circuit).

... That is, no activity pattern will precisely duplicate any other pattern, but the patterns will settle into attractor basins in the phase space. (I believe that we will find attractor basins instead of virtually random trajectories because organisms are relatively predictable. The behavioural regularities have to be caused by something other than near random events.

La afirmación de Ledoux (1996) de que las emociones deberían estudiarse como unidades funcionales independientes va en la misma línea de la cita de este autor, de Hardscatle. El concepto de emoción básica de Ekman, Tomkins, Johnson-Laird, Oatley, Plutchik, Frijda se presta a una reinterpretación en el sentido que, a continuación, vamos a explicitar. En opinión de Ackerman et al. (1998: 92) un pequeño grupo de emociones: la alegría, la tristeza, la ira, el interés, el miedo gozarían, desde el punto de vista neurológico, del estatus de subsistemas dentro de un circuito emocional cuya principal característica sería su naturaleza modular, lo que equivale a hablar de múltiples fuentes de información y de su interacción. Y, siguiendo una idea ya enunciada años antes por Fodor (1983), los módulos atañen, principalmente, a «input processes and the transduction of sensory and perceptual information». Con la maduración del cerebro y, en particular, de áreas como el hipocampo y el lóbulo frontal, la emoción interacciona, cada vez más, con la cognición, vinculándose las emociones así a un caudal de pensamientos e imágenes a medida que el sujeto avanza en su proceso de socialización. Su dependencia de subsistemas de naturaleza perceptiva y atencional explicaría que este pequeño grupo de emociones aparezca a una edad muy temprana de la infancia (la ira, la alegría, el interés, la tristeza en los primeros cuatro 
meses de vida; el miedo entre los siete y nueve meses de vida). Pero, además, los gestos faciales que nos permite reconocerlas son universales. Y cada emoción cumple, además, una función fundamental en la supervivencia: la orientación y exploración, la evitación en actitud de defensa, etc.

Pretendemos, pues, ofrecer un enfoque, en términos perceptivos, de las aportaciones sobre la emoción hechas desde la Neurología y desde la Psicobiología, que nos ayude a explicar las diferencias lingüísticas que encontramos en el nivel textual, según la emoción que domina el acto enunciativo. Vayamos, pues, por partes.

\section{La emoción desde la Neurología y la Psicología. Hacia un enfoque perceptivo e integrador}

La corteza cerebral (con sus distintas áreas: visual, auditiva, somática) asumiría el procesamiento de los estímulos perceptivos, creando una representación detallada al procesar los datos de una modalidad sensorial; imagen que, a su vez, es enviada a las zonas corticales adyacentes, encargadas de integrar los estímulos de las distintas modalidades sensoriales en una representación mucho más compleja. En cambio, la amígdala -el núcleo del circuito límbico, ya que genera reacciones rápidas que han permitido la supervivencia de nuestra especie- orienta la atención hacia rasgos muy concretos del estímulo que, precisamente, por su carácter sobresaliente, permanecen de manera más intensa en el recuerdo. De hecho, las lesiones del núcleo amigdalino impiden procesar las expresiones faciales de miedo, ira, angustia o sus manifestaciones lingüísticas. El sistema tálamo-amígdala, al requerir sinapsis más breves, produce respuestas más rápidas, sin que haya que procesar toda la información y llegue a formarse una imagen completa del objeto.

El núcleo amigdalino recibe, por consiguiente, información de un amplio abanico de niveles que intervienen en el procesamiento cognitivo: tálamo, neocórtex. Y, a su vez, está conectado con muchas áreas, como por ejemplo, las áreas subcorticales responsables del movimiento motor y las regiones hipotalámicas que coordinan las respuestas endocrinas y conductuales.

Por otra parte, los estímulos procesados por la amígdala determinan la función del hipocampo, que se encarga de proporcionar un contexto; la amígdala, al seleccionar previamente algunos rasgos del estímulo, influye, pues, en las posibles relaciones contextuales. Ledoux (1996: p.182183) describe de manera sencilla el papel de ambas vías neuronales: (1) 
tálamo-amígdala, una ruta de transmisión mucho más rápida; (2) corteza cerebral-amígdala y (3) la relación amígdala-hipocampo:

Imaginemos, en cambio, que notamos una forma curva y delgada en el camino. La curvatura y la delgadez llegan al núcleo amigdalino desde el tálamo, mientras que sólo la corteza distingue a una serpiente enroscada en una rama curva. Si es una serpiente, el núcleo amigdalino lleva ventaja. Desde el punto de vista de la supervivencia es mejor responder a sucesos potencialmente peligrosos como si fueran auténticos que no reaccionar. El riesgo que comporta tratar a una rama como a una serpiente es menos costoso a largo plazo que el precio que hay que pagar por tratar a una serpiente como si fuera una rama.

En un experimento sobre el condicionamiento del miedo, el contexto comprende todos los estímulos presentes que no son el estímulo condicionado explícito. En otras palabras, el estímulo condicionado está en primer plano: es el estímulo más destacado y previsible con respecto a la descarga eléctrica. El resto de los estímulos se encuentran en segundo plano respecto al estímulo condicionado y constituyen el contexto...El conejo que huía del zorro se condicionó no sólo a los estímulos que de inmediato se asociaron directamente a la llegada del depredador-verlo, olerlo y escuchar los sonidos que emitió al atacar-sino también el lugar en el que el encuentro tuvo lugar: el abrevadero y las proximidades... La lesión hipocámpica eliminaba selectivamente las respuestas del miedo provocadas por los estímulos contextuales sin afectar a las respuestas del miedo provocadas por el sonido.

El hipocampo cumpliría un papel determinante en la formación de una memoria explícita; las lesiones en el hipocampo no sólo impiden la posibilidad de relacionar los estímulos con el contexto espacio-temporal o con el cotexto semántico sino, también, bloquean el acceso a otros fragmentos de experiencias almacenadas y su posible cotejo con entradas de información nueva; contraste que facilita, sin duda, el reconocimiento del objeto.

En un trabajo reciente, Skardá (2000) señalaba muy bien el punto ciego en las teorías perceptivo-cognitivas actuales: la ausencia de engarce entre las cualidades observadas que confieren al objeto o suceso una articulación y la descripción de la actividad neuronal. La mayoría de teorías perceptivas, en un intento por articular el nivel ontológico y el nivel de la percepción, atribuyen al percepto el estatus de ser una copia de lo que vemos. Sin embargo, la percepción del color, por ejemplo, no tiene correlato alguno en los fenómenos físicos con los que interaccionan nuestros ojos a diario. Para Skarda, la realidad nos ofrece, como observadores de la misma, en un proceso de aprehensión directa a través de los órganos sensoriales, un contenido rico y complejo pero indiferenciado y carente, por lo tanto, de toda estructuración. Por consiguiente, el proceso de articulación del percepto en rasgos vendría, sin embargo, modulado por la actividad neuronal. 
La actividad neurológica se presenta, pues, en forma de una dinámica de sistemas, responsable, en última instancia, de la articulación del percepto. Ledoux (1996), Panksepp (1998) hablan de diferentes subsistemas neuronales en el reconocimiento de las emociones; en otras palabras, en el procesamiento de las emociones intervienen áreas distintas del cerebro. Por ejemplo, la felicidad, la tristeza y el disgusto conllevan una mayor activación sináptica en el tálamo, en el córtex medio prefrontal y en las estructuras temporales anterior y posterior, como han puesto de manifiesto las investigaciones de Lane et al. 1997.

Así pues, estos subsistemas a los que, a continuación, nos vamos a referir implementan funciones perceptivas diversas: (1) sobre las conexiones sinápticas amígdala-tálamo descansa la función perceptiva del foco de atención; la amígdala puede activarse con independencia de las respuestas corticales a los estímulos procesados; hace ya algunos años que Derryberry y Tucker (1994: 191-192) planteaban que la atención estaba controlada por la motivación; (2) sobre la conexión de la corteza cerebralamígdala descansa el reconocimiento de la figura; (3) en la relación amígdala-hipocampo: la creación de un contexto, esto es, el fondo sobre el que destaca la figura, al integrar diversas experiencias perceptivas en episodios o sucesos discretos (McClelland, McNaughton \& O'Reilly 1995).

La propia actividad neuronal confirma esta correlación entre funciones perceptivas y áreas cerebrales. El estudio de Engel et al. (1992) establece una diferenciación entre dos tipos de neuronas: por un lado, aquellas redes de neuronas que funcionan como receptores responden a rasgos particulares del estímulo físico, operando de modo aislado unas de otras. Este tipo de neuronas contribuye a la fragmentación del contenido sensorial indiferenciado; es decir, a una discriminación analítica de los atributos del objeto, como si lo pasáramos por un escáner. Las neuronas del córtex visual se activan, pues, ante un rasgo u otro. En cambio, existe una segunda clase de neuronas que cumple una función distinta: la de ser postreceptoras. Cada neurona postreceptora recibe entradas de información de varias neuronas receptoras - por ejemplo, información sobre la zona central y sobre la parte periférica de la retina- lo que activa un mecanismo de contraste, de tal manera que es, en esta segunda fase, cuando los rasgos adquieren entidad como tales rasgos.

Si retomamos el problema de la percepción del color, la discriminación del color rojo no viene dada por una frecuencia particular de la luz, aislada, sino por su contraste con otras frecuencias de luz. El trabajo de Skardá proporciona, pues, un fundamento, al replantear la teoría perceptiva desde otra óptica, a la correlación entre cualidades perceptivas y funcionamiento neuronal, haciendo de la noción de contraste un concep- 
to nuclear. Pensemos, también, en la analogía con la Lingüística. Para Saussure, el valor de un signo procedía del contraste con los demás signos del sistema y de las diferencias que revelaba, de tal modo que el signo es, ante todo, una entidad negativa. Además, este tipo de neuronas postreceptoras mantienen un feedback entre sí.

Tal vez, sea necesario matizar que la teoría de Skardá no resta importancia a las formas bajo las que se presenta la realidad pero, al mismo tiempo, pone de manifiesto la capacidad del sistema neuronal y de las zonas anatómicas para dotar de una estructuración a la información aprehendida a través de los sentidos. La flexibilidad de esta teoría en su reinterpretación de la noción de percepto resulta evidente en lo que respecta al tema de la emociones, ya que en muchas de ellas interviene un fuerte componente sociocultural.

Qué duda cabe de que ambas corrientes, la Psicología Cognitiva (Solomon 1976; Frijda 1986; Frijda \& Mesquita 1998; Oatley \& Johnson 1987; Ortony, Clore \& Collins 1988; Mandler 1990 y la Psicobiología (Darwin 1872; William James 1884; P. Ekman 1992), han puesto el énfasis en criterios diferentes en la definiciones que cada una de ellas ha dado, respectivamente, de la experiencia emocional.

Vamos a considerar, pues, en primer lugar, los desarrollos más recientes de la Psicología cognitiva en relación al obj to que nos ocupa. Los Psicólogos cognitivistas han incidido, sobre todo, en la valoración del suceso percibido que media entre el estímulo y la emoción experimentada. Yepes \& Aranguren (1996: 47) definía los sentimientos como «la conciencia de la adecuación o inadecuación entre la realidad y nuestras tendencias. Es decir, los sentimientos son perturbaciones de la subjetividad». En este sentido, quisiéramos entresacar una frase de Ledoux (1996; 1999: 138) que puntualiza bien qué es un sentimiento:

$\mathrm{Y}$ aunque todos los animales tienen alguna versión de estos mecanismos de supervivencia en sus cerebros, creo que los sentimientos sólo pueden producirse cuando un mecanismo de supervivencia está presente en un cerebro que también tiene la capacidad de consciencia. Puesto que la consciencia es un desarrollo reciente desde el punto de vista evolutivo, los sentimientos llegaron después que las respuestas... Pero diré que la capacidad para tener sentimientos está directamente relacionada con la capacidad para tener conocimiento consciente del yo y de la relación de éste con el resto del mundo.

Bastantes años antes, Mowrer \& Hobart (1960: 307) descalificaban el viejo dualismo entre emoción y lógica: «the emotions do not at all deserve to be input into opposition with intelligence; themselves a high order of intelligence». Ha habido algunos intentos de abordar la emoción en términos de una estructura cognitiva, altamente abstracta. 
Por ejemplo, Wierzbicka (1996: 180) en su trabajo definía la emoción como «un scénario prototypique qui ne décrit pas une situation externe, mais une structure cognitive hautement abstraite». A la teoría de esta lingüista se le puede hacer una crítica que no deja de ser certera, desde nuestra opinión: tales escenarios carecen del grado de abstracción necesaria; no son, pues, sino un haz de rasgos sémicos que nos remiten a las definiciones clásicas de las pasiones dadas por Aristóteles en su Retórica y por otros filósofos posteriores. Para Solomon (1976: 182), las emociones responden a una lógica de intenciones que se asimilaría a la estructura de una acción racional y requieren capacidad de abstracción:

But unlike feelings, emotions are rational, presupposing a system of purposiveness logic, and intelligence that far more resembles the structures of rational action than the phenomena of bodily feelings.

La valoración y el estado emocional que provoca en el sujeto da paso, a su vez, a la actuación. Para Frijda (1993), la emoción se distingue del afecto en una predisposición hacia la acción «hacia» o «contra» un objeto dado, ya sea real o imaginario, por parte del sujeto que la experimenta. La función evaluativa es, por consiguiente, el núcleo central de la emoción.

\section{La interacción de la emoción con las funciones cognitivas: percepción, atención, memoria y conducta}

En el libro coordinado por Kitayama \& Niedenthal (1994) encontramos algunas reflexiones que suscitan nuestra atención sobre la interacción de la emoción con estas funciones cognitivas.

Bastantes años antes, ya Solomon (1976) había intentado describir la estructura de los diferentes tipos de emoción valiéndose de conceptos perceptivos: (a) foco; (b) figura-fondo; (c) distancia; (d) orientación. En realidad, cada uno de estos parámetros tiene su correlato en los posibles circuitos de actividad neuronal, si nos atenemos a la enorme complejidad del sistema límbico a la que aludíamos al comienzo del artículo; podemos, entonces, hablar de una dinámica de sistemas con asiento en diversas zonas o áreas neuronales, susceptibles de erigirse en punto de partida de una excitación a través de las conexiones sinápticas, lo que deparará, en última instancia, en una reacción emocional.

\subsection{Emoción y atención: el desplazamiento del foco y la redundancia}

El desplazamiento del foco, que con frecuencia es asimilado a una lente de zoom, requiere, necesariamente, de una operación cognitiva como la 
activación. En la base de toda experiencia emocional hay una gran carga de excitación (energía) o mínima, según el estado emocional, que afecta al sistema nervioso simpatético y a las áreas corticales_tradicionalmente, ha sido llamada arousal. Tiene su expresión en las escalas léxicas (ira-rabia; susto-miedo-horror) y en la intensidad de las respuestas fisiológicas y motoras. Constituye la base de algunas expresiones metafóricas, que hablantes de lenguas muy diferentes acostumbran a utilizar: «Lo que me dices es descorazonador»o «Estalló (explotó) en ira», «Está hirviendo de ira». En los dos últimos ejemplos, el cuerpo es asimilado a un recipiente con un fluido en su interior, la emoción, que ejerce presión y pugna por salir.

Pero, sobre todo, el potencial de arousal energiza o amplifica algunos procesos psicológicos (Kitayama \& Howard 1994). Cabría hacer una precisión y deslindar dentro de la propia noción de arousal -como han apuntado Derryberry \& Tucker (2000)-dos modos: activación y excitación. Estos dos modos tienen lugar en hemisferios distintos: la activación, en el hemisferio izquierdo cuyo papel en el control de las funciones motoras ha quedado más que manifiesto a través de la extensa bibliografía clínica y la excitación, en el hemisferio derecho en el que residen facultades como el reconocimiento visual. En ambos hemisferios, intervienen neurotransmisores diferentes: en el hemisferio izquierdo, sustancias como la norepinefrina y la serotonina; en el hemisferio derecho, la dopamina. Tucker \& Williamson (1984: 189) han señalado que la naturaleza distinta de los neurotransmisores conlleva diferencias en la actividad neuronal, lo que se traduce, a su vez, en una distinción, a nivel cualitativo, en el procesamiento de la información cerebral: en el hemisferio izquierdo, el procesamiento se realiza de forma secuencial y la información redundante, almacenada en una memoria de plazo corto, hace posible que el proceso pueda llegar a automatizarse, ya que el volumen de información procesado cada vez es pequeño. La repetición asegura la retención de la información, el tiempo suficiente, para la ejecución de las operaciones seriales necesarias y para que el procesamiento se complete. La reacciones emocionales a las que hemos aludido adquieren, pues, un carácter casi automático, y así las conductas de evitación, asociadas a estados que conllevan una cierta vigilancia, se activan ante señales concretas, de tal manera que éstas adquieren el estatus de información estereotipada y las respuestas, a su vez, el carácter de rutinas, esenciales para el desarrollo de habilidades o destrezas cognitivas. Aunque en un nivel extremo pueden producir estereotipias, de naturaleza ya patológica, como las que se dan en las obsesiones compulsivas. Las estereotipias, las rutinas facilitan, al mismo tiempo, la activación de estrategias especulares de imitación. 
...A redundancy bias causes the control of the information flow to be determined by the brain's current information stores: The current content of the information channel serves as a reference for further processing (Tucker \& Williamson 1984: 196).

En el hemisferio derecho, la realización de un proceso cognitivo de síntesis, de atribución de un significado emocional al objeto, requiere de un procesamiento en paralelo de la información y una organización reticular de los conceptos. Un segundo circuito neuronal iría desde el córtex (del córtex frontal y posterior) a la amígdala, lo que supone un camino más largo y más lento, puesto que el número de conexiones sinápticas es mayor.

La noción de arousal es reconducida por Easterbrook (1959) hacia una teoría perceptiva, de manera que, bajo cada modo, activación/excitación, subyace una operación perceptiva cualitativamente distinta: activación (el desplazamiento del foco) y el reconocimiento o interpretación de la figura (excitación). Tomkins (1962; 1980) incidía en las diferencias, en lo que se refiere a ese punto, entre emociones básicas como la ira, el miedo, la tristeza, el disgusto y la felicidad, en lo que respecta al predominio de la focalización de determinados rasgos o el reconocimiento de la figura.

En la reacción del miedo no llega a haber una percepción consciente de la figura sino que nuestra atención parece quedar fijada en algunos rasgos concretos de la forma. La amígdala recibe información -en forma de detalles- que procede directamente del tálamo e hipotálamo y los datos son retenidos en una memoria de plazo corto; éste es el camino más corto. El área focal se caracteriza por tener escasa amplitud. El pequeño volumen de información transmitido por vía sináptica trae como consecuencia que la respuesta emocional sea bastante más rápida.

Así pues, la emoción influye en el desplazamiento del foco de atención y en la limitación del área focal; por otra parte, los estímulos localizados en el centro del foco reciben una atención más intensa y, por consiguiente, mayor relevancia (Christianson \& Loftus 1991).

\subsection{Emoción y percepción: la distinción figura-fondo}

La excitación, el otro modo del arousal (hemisferio derecho: región parietal), integra los rasgos percibidos en una representación global; se trata de un proceso cognitivo de naturaleza distinta, un proceso de síntesis. El hemisferio derecho sostiene _otra diferencia con el hemisferio izquierdo y, sin duda, una prueba más a favor de la asimetría hemisférica que se refleja en formas de organización conceptual y en tipos de procesos distintos_ un procesamiento en paralelo de la información. La excitación se 
dispara con la entrada de información nueva y el sistema perceptivo procesa los rasgos del entorno o contexto en una representación o mapa cognitivo de la escena, como han destacado Tucker \& Williamson (1984: 197):

... By allocating attention to novel environmental features, arousal allows the perceptual system to maintain a continuously revised and maximally comprehensive map of the external context.

El córtex cingulato en coordinación con la región parietal permite atribuir un significado motivacional a los objetos ubicados en el contexto externo.

There are also processes that link arousal to reward mechanisms. In describing cortical systems in attentional control, Mesulam (1981) suggested that the cingulate cortex supplements the parietal coordination of perceptual data by providing information on the motivational significance of objects in the external surround (idem, p.197)

Una lesión en este hemisferio se traduce en una alteración de las habilidades para comprender las emociones transmitidas por la expresión facial o el tono de voz, por parte del individuo que padece tal lesión.

Por consiguiente, la vía que va de la corteza cerebral -que procesa estímulos visuales, auditivos, somatoviscerales y, por consiguiente, constituye la base o fundamento para que podamos llegar a una percepción consciente del objeto- a la amígdala se erige en soporte neuronal para el reconocimiento de la figura; ello explica que una lesión en el neocórtex afecte a la capacidad de atribuir significación psicológica a los estímulos de tal modo que si antes de la lesión mostraban temor en presencia de algún objeto, animal o una persona concreta, ahora, en cambio, muestran una gran docilidad; esta ceguera psíquica se integra dentro del síndrome Klüver-Bucy.

La oscilación entre un mayor o menor grado de redundancia, nos sugiere algo sobre la capacidad representacional del cerebro que puede ir de un control interno continuo sobre el flujo de información que recibe versus dar predominio a la integración con el contexto en el que se halla encajado.

\subsection{Emoción y memoria: el contexto}

El hipocampo está conectado, por una parte, con la amígdala de la que recibe información y con el neocórtex al que envía información. Dicha área almacena experiencias perceptivas en episodios o sucesos discretos (McClelland, McNaughton \& O'Reilly 1995). Lesiones en el hipocampo o 
en las zonas adyacentes al mismo (zona entorrinal; perirrinal) traen consigo un empobrecimiento de la memoria. Hablamos de una memoria consciente, explícita y relacional; el hipocampo, debido al conocimiento que almacena sobre la relación y conexión que el estímulo desencadenante guarda con otros hechos o sucesos acaecidos en el pasado, proporciona flexibilidad a la representación cognitiva; procede, pues, a una tarea de cotejo con los fragmentos de experiencia almacenada. El hipocampo proporciona un contexto semántico a la reacción emocional. La forma en que el hipocampo organiza o categoriza la información almacenada está condicionada por el hecho de si se trata de una emoción positiva o negativa.

Bower $(1981 ; 1991)$ ha argüido que las emociones imponen una organización sobre la información semántica almacenada en forma de red. Cada emoción es conceptualizada como un nudo central que agrupa información relacionada. Bajo dicha congruencia subyace, pues, un punto de vista desde el que dos acontecimientos son vistos como similares e incluidos en la misma categoría semántica. Y esta información se desglosa en tres niveles conectados entre sí que dan cuenta de la complejidad de la experiencia: el nivel léxico (los términos relacionados con la reacción emocional; el nivel conceptual (las experiencias emocionales y los pensamientos) y el tercer nivel, la representación somática de dicha emoción, (Buck 1983, 1984 ha señalado que muy probablemente se hallan preservados los aspectos visuales, motores y somatoviscerales de la experiencia).

Isen \& Daubman (1984: 1207; 1214, respectivamente), por su parte, exponen una idea a la que líneas más arriba hemos aludido y que no deja de parecernos interesante, la clase de afecto -positivo o negativoinfluye en la organización del material cognitivo: en la manera en que los elementos o unidades son agrupadas juntas o el modo en que las relaciones son vistas; es decir, en la categorización que hacemos de las experiencias:

Thus, affective state may influence cognitive organization_may influence the way in which items or units are grouped together, or the relatedness seen in cognitive material. For example, if material is multiply encoded and multiply retrievable, it may seem to belong to multiples categories or overlapping categories; or the categories may be seen as more inclusive. (El subrayado es nuestro)

These results cannot easily be interpreted in terms of the hypothesis regarding the more basic impact of positive affect on cognitive organization _that is, increased breadth of focus, integration, or chunking of cognitive material. (El subrayado es nuestro)

Bower \& Forgas (2000: 142) explican esa predisposición, en las emociones positivas, a relacionar acontecimientos entre sí manejando el con- 
cepto de similitud, lo que influiría en la articulación y división del material cognitivo a partir de la dimensión que opone las emociones positivas a las emociones negativas: -control (emociones positivas; estado de relajamiento: menor esfuerzo cognitivo) +control (emociones negativas; estado de alerta: hay un objetivo que guía la búsqueda de información y los juicios o valoraciones):

Essentially, the idea is that bad moods motivate people to engage in controlled processing to achieve mood repair, whereas goods moods motivate subjects to engage in simplified, heuristic processing to avoid cognitive effort and maintain a pleasant affective state.

Por su parte, Bless (2000) plantea que los estados emocionales positivos son más proclives a procesar la información siguiendo un esquema y Fiedler (2000) establece la siguiente diferencia entre estados emocionales positivos y negativos:

...negative mood facilitates externally oriented, bottom up thinking, whereas good moods trigger a more constructive, top-down processing style.

\subsection{Emoción y respuestas motoras: la orientación y la distancia}

Por su parte, la relación de la amígdala con las áreas subcorticales e hipotalámicas da cuenta de las respuestas fisiológicas, cinestésicas, motoras (movimientos gestuales y corporales), conductuales. Decíamos al comienzo de este apartado, que la Psicobiología había puesto el énfasis en criterios distintos en la definición de la experiencia emocional. Para William James (1884), la emoción se reducía a una sensación visceral, la de las lágrimas, por ejemplo, deslizándose por el rostro; en la percepción del propio llanto, consistía la emoción de la tristeza; la interacción entre el cuerpo y el contexto determina cómo nos sentimos. El artículo de James iniciaba una separación radical entre emoción y cognición, de la que, evidentemente, discrepamos. La teoría de William James ha inducido a los investigadores a explorar la dimensión corporal de nuestras emociones. Sheets-Johnstone (2000) ha destacado el vacío teórico existente en la anotación de los movimientos corporales, a través de los cuales intentamos exteriorizarlas, o lo que es lo mismo, en el trazado de una dinámica diferencial. En este sentido, no habría que olvidar la raíz etimológica del término latino emotion: «movimiento interno que se proyecta hacia fuera» 0 "motivación hacia la acción», frente a la abundante bibliografía, en cambio, dedicada a la descripción de los gestos faciales y los cambios fisiológicos suscitados por los estados emocionales. 
En nuestra opinión, el componente cinético y cinestésico es parte, también, de la cognición y, de igual modo, se presta a una reinterpretación en términos perceptivo-cognitivos. Precisamente, Johnson (1987) ha reivindicado el papel que juegan los esquemas de imágenes y, con ello, la corporeidad que subyace bajo parte del significado -esquemas presentes en la percepción del entorno, en nuestros desplazamientos a través del espacio y en la manipulación física de los objetos e, independientes, de una modalidad sensorial concreta- en la comprensión y en la adquisición del significado proposicional; el esquema de una imagen ocupa una posición intermedia entre las estructuras proposicionales abstractas, del tipo sujeto-predicado, y las imágenes particulares. De acciones como entrar y salir de una habitación, ponernos o quitarnos prendas de vestir, manipular objetos y colocarlos dentro de un recipiente inferimos un esquema, el de la contención que se plasma en la orientación espacial: dentro-fuera y, también, una serie de conceptos vinculados: protección, limitación de la fuerza condicionada por las características del recipiente que lo alberga; estabilidad; invisibilidad del objeto.

Ya a Darwin (1872) le llamaba la atención que las expresiones corporales fueran las mismas, con independencia de los orígenes étnicos o culturales, y que se dieran, incluso, en personas ciegas, que carecen de la posibilidad de aprender tales movimientos por imitación visual. Es posible, pues, que ciertos parámetros de naturaleza perceptivo-cognitiva subyazcan bajo dichas respuestas motoras. Dahl (1977: 4) subraya el movimiento de contracción y de extensión como una característica fundamental de los estados emocionales. El movimiento de extensión está orientado hacia un objeto, externo al sujeto pasional en la ira, en el amor, se hace bien evidente; el movimiento de contracción supone la dirección opuesta, precisamente, un vector cuya flecha apunta hacia el sujeto que experimenta la pasión, es el caso del remordimiento o de la vergüenza.

En trabajos anteriores, Sheets-Johnstone (1966/1980; 1999) caracterizaba la fenomenología del movimiento a partir de cuatro cualidades: linealidad, amplitud, proyección y tensión. La linealidad concierne a las trayectorias que nuestros cuerpos -a través de la actitud postural que adoptan y que nos habla no tanto de una acción en curso como de cierta disposición a la acción- describen en el espacio: distanciamiento de un objeto, aproximación, movimiento contra un objeto; movimiento que finaliza en el contacto con el objeto. En esas distintas posibilidades de trayecto, el sujeto siente su cuerpo como espacio abierto o cerrado. Lo que Sheets-Johnstone denomina amplitud puede ser reinterpretado como extensión-contracción, esto es, orientación del yo hacia un objeto externo o 
inversión del sentido del vector, hacia el yo. La proyección atañe a la descarga de energía o fuerza que, unas veces, hacemos de una manera continua, de forma puntual o, con cierta cadencia, y la tensión sería la sensación de esfuerzo de la que somos conscientes en el desplazamiento. En realidad, para el entronque entre (cognición (emoción)) y lenguaje, nos interesan las cualidades propiamente espaciales:

- Orientación hacia un objeto externo/hacia el sujeto que experimenta la emoción.

- Trayectoria del movimiento: distanciamiento, aproximación, choque, movimiento de contacto.

- El cuerpo como espacio abierto o espacio cerrado.

\section{Parámetros que integran la experiencia emocional y su correlato con las leyes gestálticas y los niveles lingüísticos}

Oatley (1993: 243) consideraba que, si la emoción es un constructo, se presta a una reflexión, entonces, sobre las variables que la integran. Aceptar que la valoración o lectura del suceso percibido varía, sistemáticamente, en un pequeño número de componentes, nos conduce a una teoría estructural de la emoción. Del análisis que realizamos del suceso o acción percibida, extraemos una serie de valencias o dimensiones que nos conducirán a vivir lo acontecido bajo un estado u otro. Como muy bien han puntualizado Frijda, Mesquita, Sonnemans, Goozen (1991), la adopción de un enfoque estructuralista y el presupuesto de que la comprensión de una emoción concierne al relato nos obliga a preguntarnos por las unidades apropiadas y los niveles de análisis que deberíamos distinguir y sus posibles correlatos lingüísticos que se expresan en las emociones que difieren entre sí en unos pocos parámetros o dimensiones.

De hecho, Osgood (1979: 95-138) ha destacado algunos parámetros importantes que el análisis del léxico emocional y el lenguaje no verbal. Estos parámetros dan cuenta tanto de las emociones positivas que generan placer como de las emociones negativas que producen en el sujeto displacer y que constituyen un principio de categorización básico:

(1) Arousal: + Activación/ excitación

( + Intensidad de las respuestas cognitivas y conductuales)

(2) Atracción

(Tendencia asociativa, "hacia")

\section{- Activación/ excitación \\ (- Intensidad de las respuestas cognitivas y conductuales)}

\section{Repulsión}

(Tendencia disociativa, «lejos») 
(3) Movimiento de expansión

(Dirección hacia un objeto externo al yo)

\section{(4) +Control}

(Acción deliberada, intencional:

el yo se erige en centro articulador) _Ira

\author{
Movimiento de contracción \\ (Replegamiento hacia el yo; yo= \\ =objeto emocional) \\ (objeto evaluado $=$ espacio no cerrado) \\ - Control \\ (Acción espontánea, no intencional) \\ _Horror, sorpresa, alegría
}

Las valencias o dimensiones a las que nos hemos referido en el apartado anterior forman parte de imágenes preconceptuales desde las que nos aproximamos o distanciamos del otro. En realidad, lo que la experiencia emocional pone en juego no es sino la imagen interna que el sujeto tiene del objeto (Castilla del Pino (2000: 59):

...La vinculación afectiva no se establece directamente con los objetos sino con las imágenes de los mismos construidas por el sujeto...Así por ejemplo, en la ilusión_por ejemplo, el enfermo confunde un botón de la camisa con un insecto_se precisa de un objeto exterior, pero sobre él superpone un objeto interno, con lo cual se obtiene un objeto aparentemente externo con el significado del objeto interno superpuesto.

Por esa razón, aparecen como constantes en el léxico emocional, en el lenguaje no verbal y en el lenguaje figurativo, en las metáforas -los niveles más icónicos- a través de los cuales expresamos -quisiéramos incidir en lo siguiente, «sólo en parte»- nuestras emociones, ya que existen muchos otros mecanismos lingüístico-textuales que, hasta el momento, no han sido puestos en relación con estas valencias. Tales dimensiones (+activación/mínima activación; +control/no control; atracción/repulsión; movimiento de expansión/contracción) se prestan a ser reinterpretadas dentro de una teoría gestáltica. Carlos Inchaurralde (1997: 136) en un trabajo reciente reflexionaba sobre la emoción en términos espaciales. En la interacción de nuestro espacio personal -en esta doble vertiente, en concreto: física, psicológica- actúan ciertos procesos bajo los que subyace una ley gestáltica:

(1'a) En las interacciones cotidianas, nos ubicamos en aquellas partes de la escena en la que recibimos mayor atención: ley de la buena forma.

(1'b) Los sujetos tienden a defender el propio espacio personal y a colocarlo en una posición de dominio, por encima de los otros, haciendo del mismo el punto de referencia desde el que es valorado lo que acontece, en tanto objeto de nuestra emoción: ley de buena forma.

(2') Sentimos la predisposición a establecer vínculos con otros espacios que nos son afines: ley de la similaridad. 
(3') Aquello que integramos dentro del espacio de nuestro propio cuerpo (físico o psicológico) -y su aceptación no pone en entredicho nuestro equilibrio- pasamos a considerarlo como bueno, ya que lo sentimos como una posesión o, más aun, como parte de nosotros mismos. Así pues, en la forma de desenvolvernos en el plano emocional con otras personas, observamos nuestra tendencia a incrementar el propio espacio personal y hacer de éste una figura global: ley del cierre.

(4') Con frecuencia, los sujetos luchan por establecer una delimitación entre su espacio personal y el de los demás, aspirando en ese proceso de diferenciación, con ello, al estatus de foreground o figura de la escena: ley de la proximidad.

López García (1989: 95) planteaba que estas leyes gestálticas, que -como acabamos de ver, juegan un papel en las interacciones personales (Inchaurralde 1997: 136)- y las situaciones topológicas a las que dan lugar desempeñan, también, una función importante en la cognición lingüística hasta el punto de ser universales que tienen su plasmación en las siguientes situaciones lingüísticas:

1"a y b) El nivel de enunciación: cualquier unidad enunciada pasa a ser valorada por el contexto situacional envolvente que la recibe y sin el cual sería simplemente un signo en potencia. El nivel de enunciación se expresa en la distinción entre los conceptos de foco, diferenciación entre tema (lo conocido) y rema (la información nueva que se predica haciendo avanzar la comunicación; y en la deixis personal, espacial y temporal.

2") El nivel de concordancia consiste en que todas las lenguas del mundo expresan relaciones entre elementos mediante procedimientos formales implícitos y explícitos que se repiten en uno y en otro (igualdad)

3”) El nivel de rección expresa la determinación mutua de dos elementos que, sin embargo, no incorporan el vínculo que contraen.

4") El nivel de orden hace referencia al cotexto verbal y al hecho de que toda unidad enunciada es susceptible de ser acotada o delimitada por el texto subsiguiente; lo que tiene carácter opcional (proximidad).

Cada uno de estos procesos que atañen al «emotional involvement» se erige en correlato de una de las dimensiones que son parte de las propias experiencias emocionales y, también, de los parámetros que intervienen en la construcción de esa imagen esquemática, preconceptual, retomando la definición de Castilla del Pino que hemos citado líneas más arriba.

Ya bastantes años antes, Langacker (1983: 123-145), desde la Lingüística cognitiva, había tendido en su teorización un puente entre el nivel conceptual, semántico y el nivel sintáctico, al entender que bajo la elección de una construcción gramatical subyace un visión particular de 
la escena, y la sintaxis de la oración y del discurso no son, por consiguiente, niveles autónomos. Las propiedades del lenguaje se convierten en el espejo de otras funciones cognitivas. Langacker planteaba que las categorías y estructuras de la sintaxis oracional y discursiva simbolizan los parámetros que intervienen en la construcción de un esquema: la distinción entre figura/fondo; el foco de atención; el punto de vista; un componente subjetivo; la articulación de la escena en sí bajo un esquema. Nos proponemos, pues, justificar las interrelaciones que ofrecemos al lector en el cuadro que aparece líneas más abajo.

La selección dentro de una escena oracional o textual de la figura se halla condicionada por el aspecto compacto que ofrecen distintos puntos espaciales, en relación a un valor concreto que, al presentar ligeras oscilaciones, confiere a esos puntos una continuidad y, por consiguiente, el carácter de zona espacial delimitada por unos bordes; entrando así en una relación de contraste y diferenciación con otras zonas espaciales en las que no se da dicha continuidad. Cuando hablábamos del «arousal» bajo la forma de excitación (hemisferio derecho: región parietal, córtex cingulato), nos referíamos al procesamiento en paralelo de la información, a la sensibilidad de las neuronas para proceder a una discriminación entre rasgos conocidos y nuevos; y a un neurotransmisor como la norepinefrina. La excitación produce una orientación del sistema perceptivo hacia el procesamiento de los estímulos nuevos en distintos puntos espaciales.

En cambio, el «arousal» bajo su forma de activación (hemisferio izquierdo: córtex frontal; la conexión del córtex frontal con los ganglios basales (la dopamina actúa de neurotransmisor; la función del córtex posterior) produce una redundancia informativa, esto es, el procesamiento reiterado de unos rasgos concretos que son almacenados en una memoria de plazo corto generando una serie de rutinas conductuales. Sin la redundancia informativa, no sería factible el estrechamiento del foco de atención, en estados emocionales de alerta como el miedo, la ansiedad, la ira, hasta el punto de formar un «túnel de visión», a través del cual movilizan los recursos atencionales unos pocos estímulos, los más importantes.

Por punto de vista entendemos la posición desde la que contemplamos la escena. Según el lugar en el que elegimos ubicarnos, apreciamos unas relaciones $u$ otras entre los objetos y un mayor o menor grado de proximidad o distancia entre los elementos que lo componen. Bajo la dimensión del +control /-control subyace en el primer caso un objetivo que guía la búsqueda de información del sujeto que se halla bajo el estado emocional displacentero y, por consiguiente, en alerta; en las emociones pla- 


\section{Emoción y relato}

centeras, al conllevar un fuerte estado de relajación, el procesamiento de la información se halla orientado hacia el exterior y no está guiado por alguna intención del sujeto.

\begin{tabular}{|c|c|c|c|c|c|}
\hline Área cerebral & $\begin{array}{c}\text { Experiencia } \\
\text { emocional: } \\
\text { Dimensiones }\end{array}$ & $\begin{array}{c}\text { Proceso } \\
\text { cognitivo }\end{array}$ & Ley gestáltica & Nivel lingüístico & $\begin{array}{l}\text { Mecanismos } \\
\text { lingüísticos }\end{array}$ \\
\hline $\begin{array}{l}\text { Hemisferio } \\
\text { derecho: lóbulo } \\
\text { parietal, córtex } \\
\text { cingulato; } \\
\text { córtex posterior }\end{array}$ & $\begin{array}{l}\text { Arousal: excitación } \\
\text { Emociones (+excitación) } \\
\text { Emociones (-excitación) }\end{array}$ & $\begin{array}{l}\text { - Proceso de } \\
\text { síntesis } \\
\\
\text { - Interpretación } \\
\text { perceptiva del } \\
\text { estímulo. } \\
\\
\text { - Procesamiento en } \\
\text { paralelo. } \\
\end{array}$ & $\begin{array}{l}\text { Ley de la buena } \\
\text { forma: el yo se } \\
\text { erige en punto de } \\
\text { referencia en la } \\
\text { interpretación de } \\
\text { lo que acontece }\end{array}$ & Nivel enunciativo & $\begin{array}{l}\text { Deixis personal y } \\
\text { espacio temporal }\end{array}$ \\
\hline $\begin{array}{l}\text { Hemisferio } \\
\text { izquierdo. } \\
\text { Circuito: } \\
\text { tálamo- } \\
\text { hipotálamo- } \\
\text { amigdala }\end{array}$ & $\begin{array}{l}\quad \text { Activación } \\
\text { Emociones } \\
\text { (+activación)/Emocio } \\
\text { nes (-activación) }\end{array}$ & $\begin{array}{l}\text {-Proceso analítico } \\
\text { de los rasgos del } \\
\text { estímulo. } \\
\text {-Procesamiento } \\
\text { serial y orientado }\end{array}$ & $\begin{array}{c}\text { Ley de la buena } \\
\text { forma: tendencia } \\
\text { a ubicarse en } \\
\text { aquellas partes } \\
\text { de la escena que } \\
\text { reciben mayor } \\
\text { atención }\end{array}$ & Nivel enunciativo & $\begin{array}{l}\text { Procedimientos de } \\
\text { focalización }\end{array}$ \\
\hline 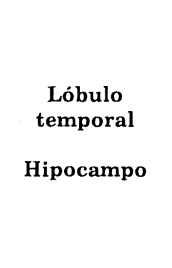 & $\begin{array}{l}\text { Atracción/repulsión } \\
\text { Tendencias } \\
\text { asociativas/disociativas }\end{array}$ & $\begin{array}{l}\text {-Cotejo y conexión } \\
\text { con otros } \\
\text { fragmentos de } \\
\text { experiencias } \\
\text { emocionales } \\
\text { similares. } \\
\text {-Memoria } \\
\text { consciente, } \\
\text { explícita }\end{array}$ & $\begin{array}{l}\text { Ley de la } \\
\text { similaridad: } \\
\text { sentimos } \\
\text { predisposición a } \\
\text { establecer } \\
\text { conexión con } \\
\text { otros espacios } \\
\text { que nos son } \\
\text { afines }\end{array}$ & Nivel de concordancia & $\begin{array}{l}\text { Mecanismos de } \\
\text { cohesión y } \\
\text { coherencia. }\end{array}$ \\
\hline $\begin{array}{l}\text { Circuito: } \\
\text { proyección del } \\
\text { neocórtex en la } \\
\text { corteza de } \\
\text { transición: } \\
\text { zonas perirrinal, } \\
\text { hipocámpica,ent } \\
\text { orrinal- } \\
\text { (conexión con } \\
\text { la amígdala ) }\end{array}$ & $\begin{array}{c}\text { Expansión / } \\
\text { contracción } \\
\text { Orientación hacia un } \\
\text { objeto externo e } \\
\text { integración / } \\
\text { retracción hacia el yo }\end{array}$ & $\begin{array}{l}\text { Interrelación de los } \\
\text { datos que proceden } \\
\text { de los diferentes } \\
\text { modos sensoriales } \\
\text { en la corteza de } \\
\text { transición en una } \\
\text { representación más } \\
\text { compleja y conexión } \\
\text { con el núcleo } \\
\text { amigdalino: núcleo } \\
\text { de una memoria } \\
\text { implícita }\end{array}$ & $\begin{array}{l}\text { Ley del cierre: } \\
\text { tendencia a } \\
\text { incrementar el } \\
\text { propio espacio } \\
\text { personal y a } \\
\text { hacer de éste una } \\
\text { figura global }\end{array}$ & Nivel de rección & $\begin{array}{l}\text { Presuposición e } \\
\text { implicaturas }\end{array}$ \\
\hline $\begin{array}{l}\text { Circuito: } \\
\text { Corteza } \\
\text { prefrontal- } \\
\text { núcleo } \\
\text { amigdalino }\end{array}$ & $\begin{array}{l}\text { Control } \\
\text { Emociones (+control } \\
\text { interno)/emociones (- } \\
\text { control interno) }\end{array}$ & $\begin{array}{l}\text { Planificación y } \\
\text { ejecución de las } \\
\text { acciones } \\
\text { emocionales }\end{array}$ & \begin{tabular}{|l|} 
Ley de la \\
proximidad: \\
delimitación del \\
propio espacio \\
personal y \\
tendencia a \\
ocupar la \\
posición de \\
figura \\
\end{tabular} & Nivel de orden & $\begin{array}{l}\text { Mecanismos } \\
\text { retórico- } \\
\text { argumentativos: } \\
\text { conllevan una } \\
\text { gradación y } \\
\text { dirección de la } \\
\text { fuerza } \\
\text { argumentativa: } \\
\text { dibujo de la figura }\end{array}$ \\
\hline
\end{tabular}

Podríamos interpretar los rasgos lingüísticos que sobresalen en un relato en el que predomina una emoción concreta desde el predominio o transgresión de alguna de estas cuatro leyes; teniendo en cuenta que en la emoción hay una percepción y valoración de lo que acontece, previa a 
la propia reacción emocional. La neırología también puede inspirar a la Psicología.

\section{Emoción y relato}

\subsection{La inscripción de la ira en el relato}

Aristóteles definía la ira como «un apetito penoso de venganza por causa de un desprecio manifestado contra uno mismo o contra los que nos son próximos, sin que hubiera razón para tal desprecio». La fenomenología de esta pasión posee rasgos que la individualizan respecto a otras pasiones: (a) la gran descarga de energía que la persona airada manifiesta en sus gestos y movimientos corporales: la contracción de los labios, la presión de las mandíbulas; la dilatación de las aletas de la nariz; el cierre de los puños; (b) la persona airada no adopta una conducta de evitación sino todo lo contrario: para hacer frente a aquel que le es hostil, intenta acceder a una percepción completa de la escena -ojos muy abiertos y fulgurantes-, un fruncimiento muy marcado de la frente, causado por algo o alguien que representa una fuerza que se le opone y cierta concentración a nivel mental; (3) en el plano cinético, el cuerpo se halla ligeramente inclinado hacia el contrincante, en actitud agresiva, y dispuesto a precipitarse en una acción inmediata. Podemos hablar, pues, de un movimiento de expansión orientado hacia un objeto externo, lo que conlleva una cercanía/contacto con el objeto-estímulo y la defensa, al mismo tiempo, del espacio personal que tiende a cerrarse y, si es posible, a la inclusión del objeto dentro del mismo.

El esquema de imagen que se desprende de las situaciones de ira puede ser el siguiente: +Arousal (en su modalidad de +activación y no de +excitación); +Control; +Repulsión; Movimiento de expansión hacia un objeto. En la expresión emocional, el sujeto airado lucha por ocupar la posición de figura de la escena y relegar al otro, a un segundo plano, en términos de la teoría de la Gestalt, el fondo, que en sí resulta menos perceptible y presenta menor grado de resolución y contraste.

De ahí, que la persona airada emplee frases hechas y modismos que satisfacen una doble condición: en primer lugar, la de ser relevantes en el sentido que Sperber y Wilson atribuyen (1986) a la noción de relevancia: el mínimo coste de procesamiento cognitivo; se trata de frases hechas o modismos que cumplen una doble condición: gozan de una transparencia icónica y relegan, desde el punto de vista enunciativo, al adversario y sus enunciados a un segundo plano _en el ejemplo (1), aparece la expre- 
sión andarse por las ramas que, desde un punto de vista espacial, hace referencia a la parte periférica del objeto. Y su acepción es «no ir directamente a lo que es importante, el objetivo de nuestra comunicación»; otras veces, se trata de frases hechas y modismos cuyo significado se halla muy reforzado por el aprendizaje pragmático de expresiones similares que comparten un mismo rasgo sémico: cuentos chinos («historias que nadie las cree») (1); cuento de la lechera («ilusiones»); tener mucho cuento («exageración desmedida sin correspondencia con la realidad»); ir con cuentos («chismes»); todas estas expresiones nos transmiten la posición de un locutor que atribuye escaso grado de certeza al interlocutor que le suscita ira y bascula en su valoración del enunciado entre lo probable y lo improbable (modalidad epistémica). Ambos ejes: posible-imposible y probable-improbable, correspondientes a las modalidades alética y epistémica, respectivamente, nos ofrecen una imagen, con escasa resolución, del sujeto del enunciado o del enunciado; no hay demasiada perceptibilidad puesto que carece de realidad ontológica.

También, una forma de referirse a la persona que suscita nuestra ira es mediante el uso de proformas: (2) ese tipo; cosas que carecen de lógica o el uso de términos con un valor genérico, de indefinición: (3) toda tu historia política, por ejemplo, o sentimental o lo que sea no cuentan para nada; (4) eso es sólo palabrería.

Veamos algunos ejemplos:

(1)

_H: Presidente, ¡Quiero cambiar mi voto!

_B: ¿Qué? ¿Qué?

_H: Ya lo ha oído

_B: ¿Quê le ha hecho cambiar? ¡Todos esos cuentos chinos! Si nuestro amigo escribiera novelas policíacas se forraría. ¡Hasta el abogado sabía que no tenía ninguna posibilidad! ¡Desde el primer momento sabía que era un caso perdido! ¡Hay que fastidiarse! Tenía un abogado, ¿no? La defensa era él y no usted. ¿A qué viene tanto rollo? ¡No comprendo cómo seguimos escuchándole! (Director: Sydney Lumet: Doce hombres sin piedad. 1957).

(2)

_A: Sin embargo, supongamos que le oyó decir ¡Voy a matarte! ¿Cuántas veces hemos dicho algo parecido? Es posible que miles ¡Eres un canalla! ¡Vuelve a hacer eso y te mato! ¡Eres un canalla! ¡Mereces morir! ¡Dale, Roky, dale! Eso no significa que matemos de verdad.

B: ¡No se vaya por las ramas y trate de liarme! La frase que gritó el chico es ¡Voy a matarte! Y la gritó a pleno pulmón. ¡No me diga que no va en serio! Cualquiera que diga eso como él lo dijo, sí va en serio.

_C: Yo no estoy tan seguro. Hace un par de semanas estuve discutiendo con un compañero muy antipático. Me llamó idiota y le amenacé. 
_B: Ese tipo intenta hacerles creer cosas que carecen de lógica. El chico gritó que iba a matarle y le mató.

(Ídem)

(3)

- Michi: No, no, es un personaje molesto. La muerte de papá no tiene nada que ver. Yo la historia que conozco muy claramente son desde el año 62; realmente, empieza en el momento en que oigo, presencio, escucho las primeras discusiones sobre Leopoldo; toda tu historia política, por ejemplo, o sentimental o lo que sea no cuentan para nada; yo, el punto de referencia es...; el compañero de juegos mío era Leopoldo; y de repente, este tipo se convierte impuesto por ti, por la familia o por X, eso habría que hablarlo muy lentamente, se convierte en un personaje raro; incluso para mí, es decir, raro; es la discusión continua, son los gritos, los portazos, el alcohol mal digerido, etc.

(Director: Jaime Chávarri: El desencanto. 1976)

(4)

_B: ¡Levántese y diga por qué ha cambiado su voto! ¡Dénos una razón!

_M: No tengo por qué justificar mi decisión ante nadie. Simplemente, tengo una duda razonable.

B: Una duda razonable, eso es sólo palabrería. El chico que acaba de declarar inocente fue visto clavando esta navaja en el pecho de su padre. ¿Qué dice de esto Don Duda razonable?

(Sydney Lumet: Doce hombres sin piedad. 1957)

En una emoción como la ira, es posible observar la tendencia de cada uno de los sujetos que discuten a incrementar el espacio de la enunciación hasta hacer de éste una figura cerrada, global, que no admite fisuras, cumpliéndose así la ley del cierre. Resultan, pues, no poco frecuentes figuras como la corrección o la concesión, ya que en ambas, la información más importante y con mayor peso argumentativo aparece en un orden climático, creciente. La correctio sigue un esquema lógico del tipo: no p sino q; no p, q; p, o más bien/o mejor, q; q no/mejor p. La concesión es la aceptación de las razones del interlocutor para, a continuación, hacer alguna observación, o poner alguna objeción que dé mayor peso argumentativo a la opinión de quien está hablando.

En general, podemos relacionar la ira con esquemas figurativos que siguen un orden creciente de menos a mayor importancia y peso argumentativo en lo que respecta a la distribución de la información (5) (6) (7), lo que se refleja en el uso del léxico; y ese orden de intensidad creciente puede afectar también a la modalidad hasta el punto de producirse el desplazamiento de una modalidad a otra. El cambio, por ejemplo, a una modalidad deóntica, en su grado de obligación, cierra la pequeña discusión entablada en el ejemplo (8). En el ejemplo (9), el clímax se refleja, 
también, en la fuerza ilocutiva. En el ejemplo (9) todos los enunciados realizan actos inlocutivos directivos pero, con distinta grado de fuerza, hasta el punto de que podemos observar una gradación: interrogativo (¿Por qué habla así en ese tono a un anciano?)- admonitorio (advertencia: ¡Procure tener más respeto!)-admonitorio (amenaza: o jle parto la cara!).

(5)

A: Era un abogado de oficio, ya se lo expliqué; en primer lugar, no quería el caso Lo aceptó muy a su pesar. Es el tipo de caso que nó te da dinero, ni gloria, ni la posibilidad de ganar. No es la situación ideal para un abogado que empieza. Hay que tener fe en el cliente para organizar una buena defensa. Y, como usted acaba de decir, el no la tenía.

_B: ¡Claro que no la tenía! ¡Nadie la tendría! Es posible que ni su madre. (Director: Sydney Lumet: Doce hombres sin piedad. 1957)

(6)

- Leopoldo María Panero: Pero que te daba mucha vergüenza encontrarte con las gitanas esas que iban a la cárcel.

_ Felicidad: ¿Me daba vergüenza? Si me hice íntima de todas las gitanas y sabía todas las historias de las gitanas y eran divinas

- Leopoldo María Panero: Pues mira, yo te he oído que había veces que te daba vergüenza. Y eran unos seres adorables. Ponían canciones de Peret y era la época en que mejor me lo pasaba.

(Director: Jaime Chávarri: El desencanto. 1976)

(7)

- Leopoldo María Panero: Lo que yo veo sobre todo es la fijación que tienes con tu padre que fue médico y, desde entonces, ves una bata blanca y te quedas pasmada.

- Felicidad (su madre): Efectivamente, las batas blancas siempre me han gustado. Y he sentido muchísimo no haberme casado con un médico. Es un trauma que me ha quedado siempre.

(Director: Jaime Chávarri: El desencanto. 1976)

(8)

_A: Aún suponiendo que hubiese oído algo, con ese ruido no pudo identificar la voz

B Estamos hablando de segundos. ¡Cómo puede ser Usted tan rotundo!

_A: ¡Los testigos que pueden llevar a un muchacho a la silla eléctrica deben ser rotundos!

(Director: Sydney LUMET: Doce hombres sin piedad. 1957)

(9)

_B: Ya estoy más que harto de frases bonitas. ¿Por qué no se las vende a un periódico? Quizá allí se las paguen bien.

_D: ¿Por qué habla así en ese tono a un anciano? Al que le habla así a un anciano habría que pisotearle. ¡Procure tener más respeto! Como vuelva a hablar así en ese tono, ¡le parto la cara! (Ídem) 


\subsection{La inscripción del desprecio en el relato}

El Diccionario de María Moliner (1991) recoge la etimología, transparente, de esta palabra que procede del vocablo latino premium, «precio». $Y$ la define en los términos siguientes: «considerar una persona a otra indigna de estimación y de que se mantenga trato con ella». De ahí que ese «tener en poco a alguien» se manifieste a través de conductas que implican la negación de la atención al otro: «mirar de largo»; «mirar de lado»; "pasar de largo»; «no tomar en cuenta sus palabras». Una emoción como el desprecio supone, pues, la transgresión de la ley de la buena forma, ya que el sujeto que desprecia se coloca, intencionalmente, en una posición que, desde el punto de vista proxémico, resulta ostensiva_en el sentido que confieren Sperber \& Wilson (1986) a la palabra ostensión_ ya que, con ella, le señala, de modo explícito, su deseo de no dirigir la atención hacia él e, incluso, de excluirlo de su campo de percepción, como denotan algunas actitudes que el Diccionario de María Moliner recoge: «volver la espalda»; "volver la cara».

Este gesto ostensivo equivaldría, en el plano del discurso, a un sujeto que borra sus huellas en el plano de la enunciación cuando se ve confrontado a hablar sobre aquello hacia lo que siente desprecio. La traslación más directa del nivel proxémico al espacio discursivo sería la deixis en sus distintas formas: personal, temporal, espacial. Reparemos en el ejemplo (10) en el que Juan Luis Panero habla de Felicidad Blanc, su madre, en el abundante uso de construcciones impersonales que emplea cuando relata su funeral: se repartieron el aire y la nada; se perdieron, igual que pienso que se pierdan las mías; se perdieron como todo; hay que preocuparse de la gente mientras se vive; este es un país necrófilo y repugnante que, cuando se ha muerto la persona...; o el uso de sustantivos deverbales en función de sujeto, de tal modo que el agente de la acción puede ser omitido - esta construcción permite, también, la impersonalización: la incineración era en Bilbao porque en San Sebastián no hay máquinas para incinerar; el empleo del infinitivo, forma no personal del verbo: a mí me parece una ridiculez ir cargando con unas cenizas; o la desubicación del sujeto en el espacio del enunciado: ni angustia ni infierno respecto al fallecimiento de la madre. En el ejemplo (14) encontramos esta misma desubicación dentro del enunciado, Juan Luis Panero define a su madre como un papel de comparsa sin pena ni gloria; tampoco malo ni bueno.

De igual modo, el borrado de las huellas enunciativas se refleja en la preferencia por un léxico que pertenece a un acerbo de conocimiento genérico. Aquellas palabras de significado específico; en cuya semántica 
se plasma la visión enunciativa a través de la determinación: el valor sexual o el número; un valor axiológico, un valor aspectual o un papel actancial, resultado del acto de percepción no abundan por el motivo al que aludíamos antes: el desprecio implica una exclusión de nuestro campo de percepción y del foco de atención. En el ejemplo (11), Franz Suchomel, de la SS, define Auschwitz como una fábrica en comparación con Treblinka una cadena para la muerte, primitiva pero que funcionaba bien. En el ejemplo (12), Itzhak Dugin, superviviente de Treblinka, nos habla del léxico que los alemanes les obligaban a usar para hacer referencia a los judíos muertos: taco de madera; marioneta; muñecas; trapos en lugar de muerto o víctima. El uso de la palabra muerto o víctima conlleva haber observado la transformación acaecida: el cese de las funciones y constantes vitales, un valor aspectual, o la atribución, desde una mirada subjetiva, de un papel actancial como víctima. También en el ejemplo (13), Leopoldo María Panero, al hablar de su padre, con quien tenía muy mala relación, acaba definiendo la figura de su padre como una mano inmensa, lo que fue Leopoldo Panero; una palabra cuyo significado no explicita ningún rasgo sémico: aspectualidad; determinación, valor axiológico o papel actancial.

En el nivel retórico, quisiéramos destacar el uso de un estilo de pensamiento tendente a la sentencia, a la máxima; detrás de la máxima, de la sentencia, se esconde la opinión no de un grupo o colectivo concreto sino, todo lo contrario, de una masa que permite al sujeto enunciativo anclarse en la pura exterioridad, al margen de cualquier valoración individual: el mundo gira así; la vida es dura, ejemplo (10).

10)

(Está hablando de su madre, Felicidad Blanc)

- Juan Luis Panero: Murió el 30 de octubre de 1990 en San Sebastián (ARRASTRA LOS SONIDOS Y ADOPTA EL TONO DE UNA CRÓNICA OFICIAL O DOCUMENTAL, tono en el que predomina la entonación o melodía propia de un género textual sobre la entonación personal): yo asistí a su incineración en Bilbao; porque en San Sebastián no había máquina para incinerar; estaba muy bien esa tarde; habíamos hablado; muy bien, claro, dentro de lo que cabe; tenía un cáncer generalizado ya; había tenido un cáncer de mama y le habían operado diez años antes y después tuvo una metástasis; y después, un día me llamaron y se había muerto; la gente se muere ¿sabe?; no solamente mi madre; la vida es dura; la incineración era en Bilbao porque en San Sebastián no hay máquina para la incineración; la ceremonia fue rápida y nada; después nos separamos y yo me volví esa noche a Barcelona; se repartieron el aire y la nada; se perdieron, igual que pienso que se pierdan las mías; se perdieron como todo; la chica nos dijo si nos las queríamos llevar; a mi me pareció que era una ridiculez ir cargando con unas cenizas; entonces, la chica muy amable dijo "aquí hay una especie de jardín"; pues, adelante y a otra cosa ¿no?; ni angustia ni infierno, el mun- 
do gira así; lo importante es qué fueron esas cenizas antes de ser; lo otro, ganas de perder el tiempo; hay que preocuparse de la gente mientras se vive; después, todo son retóricas; este es un país necrófilo y repugnante que, cuando se ha muerto la persona, todo son maravillas, monumentos y tumbas «te recordaré siempre, "te querré siempre»; no sé qué y no sé cuántos; todo, mentiras, mentiras y mentiras; me pone a cien esa historieta española.

(Director: Ricardo Franco: Después de tantos años. 1994)

11)

- Claude Lanzmann: Pero ¿Cuántas personas a la vez en una sola cámara de gas?

- Franz Suchomel (SS Unterscharführer): Yo no se lo puedo decir exactamente. Los judíos dicen 200.

- Claude Lanzmann: ¿Doscientos?

- Franz Suchomel: Doscientos ¡Imagínese un cuarto del tamaño de éste!

- Claude Lanzmann: ¡Pero en Auschwitz cabían más!

- Franz Suchomel: ¡Auschwitz era una fábrica!

- Claude Lanzmann: ¿Y Treblinka?

- Franz Suchomel: Le voy a dar mi definición. Recuerde esto: «Treblinka era una cadena para la muerte, quizá primitiva, pero funcionaba bien» (Claude Lanzmann: Shoah. 1985)

12)

- Itzhak Dugin: Cuanto más cavábamos hacia el fondo, más aplastados estaban los cuerpos. Eran prácticamente unas lonjas aplastadas. Cuando tratábamos de agarrar el cuerpo, se deshacía. Era imposible agarrarlo. Cuando nos obligaron a abrir las fosas nos prohibieron usar instrumentos. Nos dijeron «tienen que acostumbrarse a trabajar con las manos". Al principio cuando abrimos las fosas no pudimos contenernos y todos comenzamos a sollozar. Pero, entonces, se nos acercaron los alemanes y nos dieron golpes de muerte. Nos forzaron a trabajar a un ritmo desaforado durante dos días bajo golpes incesantes y sin instrumentos. Todos comenzaron a sollozar. Los alemanes incluso habían añadido que estaba prohibido emplear la palabra muerto o la palabra víctima; que eso era exactamente como un taco de madera; que eso era pura mierda, que eso no tenía ninguna importancia, que no era nada. El que decía la palabra "muerto" o "víctima" recibía golpes. Los alemanes nos obligaron a emplear con respecto a los cuerpos la palabra «figuren» («figuras»), es decir, «marionetas», «muñecas», es decir, «trapos».

(Claude Lanzmann: Shoah, documental. 1985)

13)

- Leopoldo María Panero: ...lo bajaron en una manta; todavía no había llegado el ataúd; entonces una de las manos había quedado fuera de la manta e iba dándose contra todos los escalones de la escalera; una mano inmensa, lo que fue Leopoldo Panero.

(Director: Jaime Chavarri: El desencanto. 1976)

14)

- Leopoldo María Panero: Y luego me fui a vivir a casa de mi abuela donde pasé unos años maravillosos, porque mi abuela era un encanto y, además, tenía dine- 
ro. Y mi madre, pues, no sé hacía un papel de comparsa entre mi padre y mi abuela que eran los dos puntos que yo veía claves en mi vida; un papel de comparsa sin pena ni gloria; tampoco malo ni bueno; no sé, nada, absolutamente nada; pues, era una señora que estaba a la sombra del Gran Dictador; esto, no sé, era una especie de sombra amable, amable; yo no recuerdo haber hablado con mi madre nunca hasta los 21 años.

(Director: Ricardo Franco: Después de tantos años. 1994)

\subsection{La inscripción del miedo en el relato}

Aristóteles caracterizaba el sentimiento del miedo como «un cierto pesar o turbación, nacidos de la imagen de que es inminente un mal destructivo o penoso». El miedo provoca un estado de alerta de los sentidos -en especial, la vista y el oído- de ahí la gestualidad tan marcada: elevación de las cejas; abertura de los párpados, dilatación de las pupilas -no es necesario recordar que gran parte de nuestros temores tienen que ver con la obscuridad-el temblor o tensión del cuerpo; la contracción del músculo del cuello y los músculos cutáneos; la inmovilidad o, por el contrario, la tendencia incontrolable a huir con precipitación; echamos los brazos hacia delante para alejar el objeto que nos resulta temible o los doblamos a la altura del pecho o, por encima de la cabeza, a modo de protección.

De estas breves anotaciones que conciernen a la fenomenología del miedo, extraemos un esquema de la imagen de esta pasión: (a) +control que se manifiesta en la alerta de los sentidos y en la orientación de la atención hacia el exterior. Como han señalado Moore \& Oaksford (1980), una disposición negativa dirige el foco de atención hacia la información localizada en frecuencias espaciales de baja visualidad, lo contrario de lo que sucede con los estados positivos; (b) alejamiento del objeto, ya sea bajo la forma de inmovilidad y protección del cuerpo con las manos y los brazos o huyendo; (c) se produce un estado de arousal (en su modalidad de + activación y no excitación). Con frecuencia, la respuesta emocional consiste en una reacción rápida que nos permite escapar de la situación de peligro; no hay tiempo, pues, para el procesamiento de toda la información y la percepción global de la figura. Debido a la escasa amplitud del área focal, sólo unos pocos rasgos son procesados y trasmitidos desde el tálamo a la amígdala; información, no obstante, suficiente para intuir un «posible»-quisiéramos incidir en esta palabra- esbozo del contorno del objeto, lo que Marr (1982) ha llamado el nivel 2D. Consideramos que en la emoción del miedo hay una transgresión de la ley del cierre debido a que no accedemos a una percepción consciente de la figura, a causa de 
la escasa amplitud del área focal, y el rechazo, por parte del sujeto, a integrar en el espacio de su propio cuerpo (físico o psicológico) aquello que puede poner entredicho su propio equilibrio. El miedo juega, pues, ante todo y, sobre todo, con la información implícita, implicaturas, que el lector recuperará tras un proceso inferencial que viene dado por la selección de unos términos léxicos y no otros, o se apoya en el contexto conversacional y situacional. Cuando el personaje que nos guía a través de la obscura atmósfera, llegue a obtener un saber _y con él, el lector o el espectador_y el proceso inferencial haya terminado, se produce el paso de una emoción como el miedo al terror y al horror, más intensa, pero, también, efímera y puntual a la que sucede el comienzo de una cierta aceptación.

Por ello, (Pérez Juliá 2003: 255-257) hay una serie de figuras retóricas propias de la representación o construcción de esta emoción: la metonimia o sinécdoque, la alusión, la elipsis, la perífrasis o la percontatio. En la metonimia y en la sinécdoque, a través de la relación de contigüidad cualitativa o cuantitativa entre dos objetos, procedemos a designar de modo indirecto. La elipsis no deja de ser un vacío, un agujero en la estructura semántica. La perífrasis contribuye a una definición parcial y subjetiva que nos permite asir algo de la figura; la reticencia consiste en la interrupción verbal de un pensamiento, lo que obliga al lector u oyente a reconstruirlo. Y, por último, la percontatio: una narración tan breve que omite detalles de interés que posibilitan la reconstrucción de la historia, en términos de causa y consecuencia. Comparemos el ejemplo (17) y (18). En la primera narración de Grace responde a la figura que los retóricos llamaban percontatio, ya que no hay una cohesión entre los hechos que cuenta, desde el punto de vista causal-consecutivo, por lo que sabemos que algo malo ha sucedido, un posible maltrato de Grace a sus hijos. El ejemplo 18, en la narración que hace Grace, por segunda vez, de lo que pasó aquel día, aparecen todas las acciones y su vinculación lógica, de tal manera que nos enteramos de la locura de esta madre y del homicidio que cometió, el de sus propios hijos y el de ella, pero, también, de quiénes son ellos y los otros, los intrusos.

Todas estas figuras tienen algo en común: constituyen procedimientos lingüísticos de referencia sin que el contorno o perfil del objeto se nos llegue a mostrar completo y explícitamente definido. Evidencian, pues, fisuras o aberturas del tejido textual que esperan ser suturadas, cerradas al final. Veamos algunos ejemplos

15)

GRACE: Yo misma registré esa habitación. Estaba vacía. Y sin embargo sentí que alguien más estaba allí. Una... presencia....moviéndose a mi alrededor. Y no era humana. Esos seres, sean lo que sean, nos están desafiando. A mí y a mis hijos. 


\section{Emoción y relato}

(Alejandro Amenábar: Los Otros. Guión cinematográfico. 2001, p. 88)

16)

- SEÑORA MILLS: Siempre he creído en esas cosas. Son fenómenos sin explicación...pero suceden. Todos hemos oído alguna vez una historia sobre el más allá...Y creo que, a veces, el mundo...de los muertos se mezcla con el mundo de los vivos. (alusión)

(Alejandro Amenábar: Los Otros. Guión cinematográfico. 2002, pp. 89)

17)

- CHARLES: Dime que no es verdad. Dime que la niña miente

- GRACE: No sé de qué hablas

- CHARLES: Cuéntame lo que pasó

- GRACE: ¿Lo que pasó...? No sé qué me ocurrió. Los criados se marcharon por la noche, no tuvieron el valor de decírmelo a la cara. ¡Y sabían que yo no podía dejar la casa! Desperté a los niños y les mandé a rezar y quedarse en su dormitorio hasta que cerrara las cortinas. Son niños buenos, ya lo sabes, y comprenden el peligro, pero no quisieron hacerme caso... hay días en los que se resisten a hacer lo que les digo. ¡Y había tanto que hacer! Empecé a temblar...a pesar de mí...temblaba...no debí dejar que los niños me vieran en tal estado. Nicolás se echó a llorar y Anne empezó a gritarme...Loca...me llamó loca y Dios sabe qué más cosas...cosas horribles...La mente se me paralizó...sólo sentí el martilleo...el dolor...Le devolví los gritos, cada vez más fuertes...no la dejé ni hablar...dije cosas que una madre nunca debería decir...a sus hijos...No podía más. Debes perdonarme, Charles.

- CHARLES: Yo no. Los niños.

- GRACE: Saben que los quiero. Saben que nunca les haría daño. Antes moriría. (Director: Alejandro Amenábar: Los otros. Guión cinematográfico. 2002, pp.122123)

18)

- GRACE: Al principio no entendía qué hacía con la almohada en mis manos. Ni por qué no os movíais. Entonces lo supe. Había sucedido. Había matado a mis hijos. Cogí el rifle, me lo puse en la frente y apreté el gatillo. Nada...Entonces oí vuestras risas en la habitación. Jugabais con las almohadas como si no hubiera pasado nada. Y pensé que el Señor, en su infinita bondad, me estaba dando otra oportunidad. Diciéndome: «No te rindas, sé fuerte. Sé una buena madre. Por ellos. Pero ahora....ahora ¿Qué significa todo esto? ¿Dónde estamos?

(Director: Alejandro Amenábar: Los Otros. Guión cinematográfico. 2002, pp. 159)

\section{Bibliografía}

ACKerman, Brian P.; Jo AnN A. Abe \& CARroll E. IzARD (1998): «Differential Emotions Theory and Emotional Development. Mindful of Modularity". En Michel F. MASCOLO \& Sharon Griffin (eds.) (1998): What Develops in Emotional Development? New York: Plenum Press, pp. 85-106. 


\section{Marisa Pérez Juliá}

ARISTÓteles: Retórica. Madrid: Biblioteca Clásica Gredos. 1990. Traducción de Quintín Racionero.

BELINCHÓN, Mercedes; IGOA, José Manuel y Ángel RIviÈRE (1994): Psicología del Lenguaje: Investigación y teoría. Madrid: Trotta.

BLESS, H. (2000): «Mood and General Knowledge Structures: Happy Moods and Their Impact on Information Processing». En J.P. Forgas (ed.): Feeling and Thinking: The Role of Affect in Social Cognition. New York: Cambridge University Press, pp. 201222.

Bower, Gordon H. \& Joseph P. Forgas (2000): «Affect, Memory and Social Cognition». En ERIC EICH et al. (eds.) (2000): Cognition and emotion, pp. 87-168

BRUNER, Jerome (1994): "The View from the Heart's Eye: A Commentary». En P. NiEDENTHAL \& S. KitAYAMA (eds.) (1994), pp. 269-286.

CAPPS, Lisa \& Elinor, Ochs (1995): Contructing Panic. The Discourse of Agoraphobia. Cambridge-London: Harvard University Press.

DARWIN, Charles (1872): La expresión de las emociones en los animales y en el hombre. Madrid: Alianza editorial. 1998.

DE RiverA, Joseph (1977): A Structural Theory of Emotions. New York: International Universities Press.

DERRYBERRY, Douglas (1989): “Effects of Goal-Related Motivational States on the Orienting of Spatial Attention". Acta Psychological 72, pp. 199-220.

DERriberry, Douglas \& Don M. TuCKer (1994): «Motivating the Focus of Attention». En P. Niedenthal \& S. Kitayama (eds.) (1994), pp. 167-196.

DuPUY, Jean Pierre (1992): El Sacrificio y la envidia. El liberalismo frente a la justicia social. Madrid: Gedisa.1998.

EICHENBAUM, Howard (2002): «El hipocampo y la memoria declarativa: mecanismos de representación de la experiencia". En I. MoRGADo (ed.) (2002): Emoción y conocimiento. Barcelona: Tusquets (colección Metatemas), pp. 87-106.

Christianson, S.-A. \& Loftus, E. F. (1991): «Remembering Emotional Events: The Fate of Detail Information". Cognition and Emotion 5, pp. 81-108.

EASTERBROOK, J.A. (1959): «The Effect of Emotion on Cue Utilization and the Organization of Behavior». Psychological Review 66, pp. 183-201.

Ellsworth, Phoebe C. (1991): "Some Implications of Cognitive Appraisal Theories of Emotion». En K.T. Strongman (ed.)(1991): International Review of Studies on Emotion (vol. 1). John Wiley \& Sons Ltd, pp. 143-160.

Engel, A. Et al. (1992) «Temporal Coding in the Visual Cortex: New Perspectives on Integration in the Nervous Systems". Trends in Neuroscience 15/16, pp. 218-222.

FABBRI, Paolo (1998): El giro semiótico. Barcelona: Gedisa. 1999.

FiedLeR, K. (2000): «Toward an Integrative Account on Affect and Cognition Phenomena Using the BIAS Computer Algorithm». En J. P. Forgas (ed.): Feeling and Thinking: The Role of Affect in Social Cognition. New York: Cambridge University Press, pp. 83-104.

Fodor, J. (1983): The Modularity of Mind: An Essay on Faculty Psychology. Cambridge, MA: MIT Press.

Freeman, Walter J. \& Rafael NúÑEZ (2000): «Restoring to Cognition the Forgotten Primacy of Action, Intention and Emotion». En R. NÚÑEZ y W. FrEEMAN (eds.) (2000), pp. $1-13$.

FRIJDA, Nico H. (1993): Appraisal and Beyond. The Issue of Cognitive Determinants of Emotion. Hillsdale: Lawrence Erlbaum Associates Publishers. 


\section{Emoción y relato}

Frijda, Nico H; Batja, Mesquita; Joep Sonnemans; Stephanie Van Goozen (1991): «The Duration of Affective, Phenomena or Emotions, Sentiments and Passions». En K.T. Strongman (ed.) (1991): International Review of Studies on Emotion (vol. 1). John Wiley \& Sons Ltd, pp. 187-225.

Frijda, Nico H. \& BATJA Mesquita (1998): «The Analysis of Emotions». En M. Mascolo \& S. Griffin (eds.) (1998): What Develops in Emotional Development. New York-London: Plenum Press, pp. 273-395.

HARDSCASTLE, Valerie Gray (2000): “It's O.K. to be Complicated: the Case of Emotion». En W. Freeman \& R. Núñez (eds.) (2000), pp. 237-251.

JoHnSON, Mark (1987): El cuerpo en la mente. Madrid: Debate. 1991.

INCHAURRALDE, Carlos (1997): «Space, Reference and Emotional Involvement». En S. NiEMEIER \& R. DIRVEN (1997): The Language of Emotions. Conceptualization, Expression and Theoretic Foundation. Gerhard Mercator University, pp. 135-154.

IsEN, Alice M. \& Kimberly A. DAUBMAN (1984): «The Influence of Affect on Categorization». Journal of Personality and Social Psychology vol. 47(6), pp. 1206-1217.

Kitayama, Shinobu \& Susan Howard (1994): "Affective Regulation of Perception and Comprehension: Amplification and Semantic Priming». En P. Niedenthal \& S. KITAYAMA (eds.) (1994), pp. 41-65.

KöveCSES, Zoltán (2000): Metaphor and Emotion. Cambridge University Press.

LANE, R.D \& al. (1997) "Neuroanatomical Correlates of Happiness, Sadness and Disgust». American Journal of Psychiatry 154, pp. 926-933.

LANGACKER, Ronal W. (1983): Foundations of Cognitive Grammar. Bloomington, Indiana. LEDoux, Joseph (1996): El cerebro emocional. Barcelona: Ariel/Planeta. 1999, $2^{\text {a }}$ edición. LEDOUX, Joseph (2002): «El aprendizaje del miedo: de los sistemas a las sinapsis». En. I. Morgado (ed.) (2002): Emoción y conocimiento. Barcelona: Tusquets, pp.109-134.

López García, Ángel (1989): Fundamentos de Lingüística perceptiva. Madrid: Gredos.

Marina, José Antonio \& Marisa López PenAS (1999): Diccionario de los sentimientos. Barcelona: Anagrama.

McClelland, J; McNaughton, B \& R. O'Reilly (1995): «Why there are Complementary Learning Systems in the Hippocampus and Neocortex: Insights from the Successes and Failures of Connectionist Models of Learning and Memory". Psychological Re. view 102, pp. 419-457.

Moliner, María (1991): Diccionario del uso del español. Madrid: Gredos.

Niedenthal, Paula \& Shinobu Kitayama (eds.) (1994): The Heart's Eye. Emotional Influences in Perception and Attention. San Diego: Academic Press.

Niedenthal, Paula \& Shinobu Kitayama (1994a): «Introduction». En P. Niedenthal \& S. Kitayama (eds.) (1994), pp. 1-14.

Niedenthal, Paula et al. (1994b): «Emotional Organization of Perceptual Memory». En P. Niedenthal \& S. Shinobu (eds.) (1994), pp. 87-113.

Niedenthal, Paula \& Jamin B. Habelrstadt (2000): «Emotional Response as Conceptual Coherence». En ERIC EICH et al. (eds.): Cognition and Emotion. Oxford University Press. 2000, pp. 169-203

NÚÑEZ, Rafael y Walter J. FREEMAN (eds.) (1999): Reclaiming Cognition. The Primacy of Action, Intention and Emotion. University of California, San Diego: Imprint Academic.

OATLEY, Keith (1993): «Social Construction in Emotions». En M. LEWIS \& J.M. HAVILAND (eds.)(1993): Handbook of Emotions. New York: Guilford Press, $1^{\text {a }}$ edición.

ORTONY, Andrew; Gerald L. ClORE \& Allan Collins (1988): La estructura cognitiva de las emociones. Madrid: Siglo XXI. 1996.

Osgood, Charles E. (1979): Focus on Meaning (Vol 1: Explorations in Semantic Space). The Hague-Paris: Mouton Publishers 
Panksepp, J. (1998): Affective Neuroscience: The Foundations of Human and Animal Emotions. New York: Oxford University Press.

PÉREZ JULIÁ, Marisa (2002): “Juan con miedo. Una descripción lingüística de las emociones». En Juan Martos PÉrez y Marisa PÉrez Juliá (eds.) (2002): Autismo. Un enfoque orientado a la formación en Logopedia. Valencia: Nau Llibres (Colección Logopedia e Intervención), pp. 127-158.

PÉREZ JULIÁ, Marisa (2003): «La Eternidad del fin. Una aproximación a la Retórica del miedo a partir de Los Otros del director Alejandro Amenábar». Arbor n 686 (febrero), pp. 251-264.

SheetS-Johnstone, Maxine (1999): «Emotion and Movement: A Beginning EmpiricalPhenomeological Analysis of Their Relation Ship». En R. NÚÑEZ \& W. FrEEMAN (eds.) (1999), pp. 259-277.

SkARDÁ, Christine (1999): “The Perceptual Form of Life». En R. Núñez \& W. Freeman (eds.) (1999), pp. 79-95.

Solomon, Robert C. (1976): The Passions. Indianapolis/Cambridge: Hackett Publishing Company.

SQUIRE, Larry R. (1992): «Memory and the Hippocampus: A Synthesis from Findings with Rats, Monkeys and Humans». Psychological Review vol. 99 (2), pp. 195-231.

Tomkins, S.S. (1962) Affect, Imagery, Consciousness. Vol.1: The Positive Affects. New York: Springer Verlag.

TUCKeR, Don M. \& Meter A. Williamson (1984): «Asymmetric Neural Control Systems in Human Self-Regulation". Psychological Review 91 (2), pp. 185-215.

Yepes Stork, Ricardo y Javier ARANGUREN EchevarRía (1996): Fundamentos de Antropología. EUNSA. 2003, sexta edición.

ZAJONC, R.B. (1994): "An Early Insight into the Affect-Perception Interface». En P. NiEDENTHAL \& S. SHINOBU (eds.) (1994), pp. 17-21.

WierzBICKA, Anna (1995): "Everyday Conceptions of Emotion. A Semantic Perspective». En J. Russell; J.M. Fernández-Dols et al. (eds.) (1995): Everyday Conceptions of Emotion. Kluwer Academic Publishers, pp. 17-47.

WIERZBICKA, Anna (1999): Emotions across Languages and Cultures. Cambridge University Press.

\section{Corpus}

AmenÁBAR, Alejandro (Director)(2001): Los Otros. Género: Terror. Duración 114 minutos. AMENÁBAR, Alejandro (Guionista) (2002): Los Otros. Guión cinematográfico original. Suma de Letras.

BALAGUER, Javier (Director) (2001): Sólo mía. Género: Drama: Duración: 102 minutos.

CHÁVARRI, Jaime (Director) (1976): El desencanto. Productor: Elías Querejeta. Género: Documental sobre la historia de la familia del poeta Leopoldo Panero. Duración: 1 hora, 30 minutos.

Franco, Ricardo (Director) (1994): Después de tantos años. Productor: Andrés Santana e Imanol Uribe. Género: Documental sobre la historia de la familia de Leopoldo Panero. Duración: 36 minutos

LANZMANN, Claude (1985): Shoah (Holocausto). Género: Documental, entrevistas a judíos supervivientes de algunos campos de concentración: Treblinka, Bélzec, Auchwitz y, también, algunos soldados alemanes que estuvieron en esos campos. Duración: 563 minutos.

LumET, Sydney (1957) Twelve angry men (Doce hombres sin piedad). Género: Drama. Duración 92 minutos. 